\title{
Software-export Strategies for Developing Countries: A Caribbean Perspective ${ }^{1}$
}

\author{
Ms. Pamela Y. Abbott \\ Judge Institute of Management \\ University of Cambridge, UK \\ Email: pya20@cam.ac.uk
}

\begin{abstract}
The globalisation of the software industry is seen to be driven in part by skill shortages in industrialised economies, movement of software development practices away from centralised to more distributed modes and the spread of information and communication technologies to developing countries, where skilled labour is available at lower costs. As such, a software export industry is sometimes seen as a means by which some developing countries can create competitive advantage. While many studies have explored the strategies used by some of the more successful software-exporting countries, little research has been done in locations that lack some of the basic resources deemed necessary for success in this area. This paper describes two Caribbean software-outsourcing ventures in order to explore possible softwareexport strategies available within such atypical contexts. The role of government and degree of integration of the software outsourcer into the local context are found to feature significantly.
\end{abstract}

\section{Introduction}

It has been suggested that increasing global interconnectedness, assisted to a great degree by the prevalence of information and communication technologies (ICTs) has seen the rise of a new global economic division of labour (Castells 1996). Certain types of work are seen as being relocated to developing countries, thus contributing to their economic development (Reich 1991).

One way in which such economic development may be achieved is proposed through a framework of "determinants of national competitive advantage" for a country in a given industry (Porter 1990). These include: factor conditions (the quality of a country's human resources and infrastructure needed to support the given industry); demand conditions (the strength and vibrancy of the domestic market in that particular industry); related and supporting industries (such as suppliers, that are themselves internationally competitive); and firm strategy, structure and rivalry (domestic competition in the industry and how business is established and organised in the country). The entire system is expected to create a challenging environment for firms operating in that industry, forcing innovation and raising standards, which

\footnotetext{
${ }^{1}$ This is a revised version of an in-progress paper "Implementing Global Strategies in a Local Context: Software outsourcing in the Caribbean", presented at the IFIP WG8.2 \& WG9.4 Working Conference on Information Systems Perspectives and Challenges in the Context of Globalization held in Athens, Greece, June 15-17, 2003.
} 
purportedly leads to the development of a superior product that is internationally competitive.

The emphasis in Porter's diamond is in the creation, by the country, of specialised factors of production, with the knowledge to develop and sustain the particular industry. He argues that, overall, government should play a supporting role in providing an enabling environment to sustain these four determinants. Even though the framework is developed in relation to industrialised countries and those with larger economies, Porter (1990) argues that the framework is applicable to any country at any level of development. Furthermore, he categorises developing countries as early stage economies positioned generally at the factor-driven stage of national competitiveness, a stage dependent upon local resources and unfortunately vulnerable to external influences.

The software industry is seen as a particular example of the new economic division of labour, driven both by lower costs in developing countries and skill shortages in industrialised economies and facilitated by ICTs (Carmel 1999; Herbsleb and Moitra 2001). Globalisation of the software industry is thus seen to bring the prospect of competitive advantage for developing countries (Kim et al. 1989).

India, the Philippines, Ireland, and Israel, are identified as major centres for such offshore software development activity (Lacity and Willcocks 2001). The most notable example of this phenomenon is India, with claims that its software and services export industry grew at the rate of 26\% in 2002-2003 (estimated to be worth $\$ 9.87$ billion and representing $20.4 \%$ of India's total exports) and which is thought to command $1.9 \%$ of the global software market (NASSCOM, 2003).

\subsection{India's Competitive Advantage}

The growth of India's software industry has prompted some authors to analyse the conditions leading to that success, attributing it, for example, to investment by expatriate Indians, the existence of a large, highly educated workforce steeped in a tradition of tertiary education, and the innate mathematical abilities of Indians (Balasubramanyam and Balasubramanyam 1997). Additionally, there are those who point to apparent deficiencies in demand and factor conditions, lack of significant domestic rivalries in the local software industry, and absence of locally-based interrelated and supporting industries, to argue that Porter's 'Diamond' may not necessarily apply in the case of the Indian software export industry (Krishna et al. 2000). Instead, these authors emphasise cultural context and historical legacies as in part responsible for the viability of the industry and propose their own explanatory framework meant to capture national determinants of success in the specific area of software production. These determinants, they argue, comprise people, technology, communication and organisation, all of which, they claim, Indian society has proved quite proficient at developing. Nonetheless, they also emphasise the need for government interventions to ensure that adequate resources are provided for industry growth. India's current position as the leading software-exporting developing country is seen thus to have been achieved in unique ways that are probably not so 
easily emulated by others seeking to compete (Krishna et al. 2000; Tessler and Barr 1997; Heeks 1996).

\subsection{Developing Country Strategies for Software-based Economic Development}

Other authors have sought to propose strategies for software-based economic growth for developing countries in general. Of these, most tend to recommend some combined strategy of promoting a domestic software market, in order to build local expertise and create opportunities for innovation, and also promoting a foreign export market in order to build alliances and earn foreign investment (Schware 1992; Correa 1996; Heeks 1999; Heeks and Nicholson 2002). One of the suggested frameworks analyses the viability of a developing country's software export strategy, by assessing demand conditions (the existence of markets for the software product), national vision and strategy (national policy vis-à-vis the software industry and exports), international linkages and trust (making and sustaining ties with overseas customers and suppliers), software industry characteristics (nature of competition between firms, the clustering of these firms and the ability of these firms to collaborate), and domestic input factors/infrastructure (people, the technology, financing, research and development and other unspecified intangibles) (Heeks and Nicholson 2002). The authors also promote strategies for late entrants to the market, such as newcomer developing countries, which include low cost labour and market niche specialisation. The role of government is also explicitly emphasised in six proposed factors that support the software industry: people, technology, money, infrastructure, innovation and other bureaucratic and logistic areas. The framework is suggested as a guideline for developing countries seeking to benefit from a software-export industry.

\section{Research problem and objectives}

The conditions for national competitive advantage and the software export strategies discussed in the previous section have been developed and examined within the context of India and other developing countries with fairly large software export industries or with resources capable of providing the potential for such growth, socalled 'second-tier' countries (Heeks and Nicholson 2002). These guidelines, however, would appear to offer little for countries that lack many of these basic resources/infrastructure. In order to address this apparent imbalance, this paper will describe two cases of software outsourcing to the Caribbean, a region not traditionally recognised for software production and lacking many of the factors identified by Krishna et al. (2000) and Heeks and Nicholson (2002). In this way, the paper will explore what strategies may be available within such contexts for developing a viable software export industry and how they compare with those discussed in the previous section.

\section{$3 \quad$ Research design and methods}

The data were gathered from published materials and semi-structured interviews with employees and outsourcing practitioners knowledgeable of the Caribbean context. These latter were conducted through e-mail, by telephone and face-to-face, typically of forty-five minutes in duration. Some of the sources are anonymised to protect their 
identities. Primary data sources were mainly chosen due to the under-researched nature of the Caribbean software industry. The data were analysed using NUD*IST® to extract relevant themes.

\section{$4 \quad$ Results}

Two cases of software outsourcing companies operating in the Caribbean will be presented in this section, both of which claimed to be practising nearshore software outsourcing (Abbott and Jones 2003), albeit in slightly differing ways. Nearshore software outsourcing is assumed to be the practice of offshore outsourcing from venues geographically closer to the client. The term is mentioned in various contexts, particularly with respect to the US from Mexico (e.g. Lapper and Tricks 1999) or the Caribbean (Carmel and Agarwal 2001). In the case of both ventures, one of the main reasons for choosing the venue was given as the proximity of the island to the US market, where the majority of the clients were located.

\subsection{PRTB and Nearshore Outsourcing in Barbados}

PRT (Barbados) Ltd. (PRTB), a so-called software engineering centre, was a subsidiary of PRT Group Inc., a US-based information technology solutions integrator. In 1994, Doug Mellinger, then the CEO of PRT, identified Barbados as a potential site for an offshore development centre. Contemporary reports described the PRTB concept:

"On an island in the Caribbean..., Mellinger has imported the workers, the customers, the capital, the infrastructure. He's established a partnership with the island itself that suggests how a tiny developing nation can leapfrog right over the industrial stage of economic evolution into a global, technology-based, knowledgedriven future" (Hopkins 1998).

Among the factors influencing the decision to locate in Barbados were a liberal government policy on work permits, a favourable wage structure, a low tax rate, a modern telecommunications infrastructure, an English-speaking population, and convenient access to the US (PRT, 1997). PRTB operated as an International Business Company (IBC) in Barbados and therefore was eligible for certain government incentives such as exemption from import duties and repatriation of revenues earned. PRT's targeted customers were Fortune 1000 companies in the financial services, banking and insurance sectors among others and their portfolio included clients such as J.P. Morgan \& Co., Guy Carpenter, Travellers Insurance and Prudential Insurance (PRT, 1999).

Due to a shortage of sufficiently trained software engineers in Barbados, PRTB recruited expatriates from various countries including India. PRTB's President, Srinivisan Viswanathan explained their hiring strategy as "import[ing] brain power from other parts of the world to help Barbados develop that talent internally". By 1999, approximately two-thirds of the staff were expatriates, most notably from India (King 1999).

Working with the Barbadian government, PRTB also proposed to provide: "training, internships and jobs to Barbadian computer science students" and to "develop an 
islandwide curriculum for elementary and secondary schools" (King 1999). PRTB was expected to provide the impetus needed for jumpstarting the Barbadian software industry by helping to provide new infrastructure, jobs for ancillary services, and encouragement for other IT investors (Hopkins 1998). The vision was shared by a number of PRT's customers, who supported the project with contributions, such as advance payment for future work, donated design help and construction management expertise, to the value of $\$ 12$ million (Hopkins 1998).

PRTB at first proved to be very successful, growing rapidly to 350 staff, by 1998 . At PRT Group's initial public offering, in 1997, share prices were at $\$ 13.00$ per share and rose quickly to a high of about $\$ 21.00$ per share. The company promoted its "Computer Software Engineering Centres" and onshore/offshore/nearshore approach, as a significant contributor to its success (PRT, 1997).

During 1998 and 1999, however, PRTB's profits fell sharply and staff attrition became a problem, with numbers falling to 80 members by June 1999. The loss of revenue from the Barbados subsidiary affected the Group's share price which fell to about $\$ 3.00$ by mid 1999. PRTB's losses were attributed to employee attrition, excessively quick growth and difficulty selling Barbados as a destination for software development:

"Complicating the sales challenge further, "the work in Barbados meant selling custom-solutions projects, not [programmer] bodies," says Mark Prieto, a J. P. Morgan vice-president who was lent to PRT throughout the build-out of Barbados. "Instead of asking, 'How many programmers do you need? When do you want them to start?' " says Viswanathan, salespeople needed to understand a client's business well enough to help solve its problems" (Hopkins 1999).

Interviews with nearshore practitioners, familiar with doing business in Barbados, and with the PRT undertaking, confirmed the press reports. One such interviewee commented that expatriate employment might have been unavoidable:

"Such countries, like Barbados, do not often have the calibre of software professionals that are required, hence, staff relocations are required and that means recruiting from 'other' countries."

PRTB's approach to realising the nearshore concept also came in for criticism with claims that appropriate marketing strategies had not been utilised. As interviewees explained, a special market focus may have been needed to promote small islands, such as the Caribbean states, as software exporters:

"Determine what type of projects it makes more sense to do ... Production support is do-able due to the time zone advantage as opposed to India's time zone. Connectivity problems exist in India. Better to do this type of work in Barbados."

Also, PRTB might have been better off to have invested more in developing the local workforce:

"The success[ful] implementation of an IT school in Barbados operated... in conjunction with the Barbadian Government and UWI, in 2-3 years, [would] "create and nurture' the type of employees [that were] needed. ...this was the answer."

It was also noted that, under Barbados legislation, IBC's, such as PRTB, were not allowed to trade on the local market so as to protect the local software industry, but 
interviewees felt that a more liberal government policy might have been advantageous. As one interviewee put it:

"An incorrect government policy can limit advantages - in such a business you are getting higher technology experience for clients in more advanced countries however, ...government policy is that this expertise is not allowed to be used to service local clients... In case of Barbados, for most of the near-shore development there is a total ban on local business. A more prudent country policy would be to allow at least say $25 \%$ of the revenue to be sourced from local business."

The government's involvement, however, was seen to be restricted mainly to providing an enabling environment:

“...the infrastructure must be good and the tariffs affordable. Government policy should be stable. [The operation is] dependent on expatriate expert man-power. [What] should be conducive to getting and retaining that personnel, [are] both government and business environment".

\subsection{Indusa Global, a Jamaican Nearshore Enterprise}

Indusa Global was established in 1995 by James Ram, an Indian expatriate living in the USA, in collaboration with US entrepreneur Carroll Rushing, with the aim of establishing a software development presence in the Caribbean to exploit its proximity to the USA and gain competitive advantage, by providing a "near shore alternative to offshore programming". Officials from a Jamaican government agency, the Montego Bay Free Zone, aware of Indusa's interest, approached the entrepreneurs with the possibility of making that investment in Jamaica. The island was eventually chosen because in addition to its proximity, it possessed a cheap, educated workforce of native English speakers and a functional telecommunications infrastructure.

Ram summarised Indusa's strategy:

“...we felt that the way to build [the company] would be to establish a training program, develop our own workforce and then use them to build the company. ...we thought the government would become a bigger partner if they saw us training their people and keeping them on for the long haul.” (James Ram, CEO Indusa)

This would be facilitated initially by Indian expatriates:

"The business model had it that we would bring in Indians that had been trained in India, move them to Jamaica, create an offshore business, and use the Indians as the mentors for the students when they graduated ...to incubate them and improve their skills so that they would be competitive on the world-wide market" (Caroll Rushing, Chairman of Indusa)

A training school, the Caribbean Institute of Technology (CIT), was therefore established in collaboration with the government of Jamaica (in the form of the Ministry of Trade, Industry and Communications and the Ministry of Education, through the national training agency, HEART) and Jamaican, US and UK academic institutions (University of the West Indies, Jamaica, University of Technology, Jamaica, Furman University, South Carolina and University of Hertfordshire, UK). The curriculum, was developed by the academic partners and was closely tied to Indusa's needs, focusing on the latest technological areas, such as web and Java programming. Applicants to the program were to possess at least a high-school education, but beyond that no computer literacy was mandated. As a result persons 
from all occupations and backgrounds were accepted into the program. The tenmonth course was expected to bring the complete novice up to the standard of computer programmer. The "incubation" process would then be initiated on these graduates. Indusa Global hired all of graduates of the first year and a significant percentage of the second group.

Indusa Global provided the start-up money for the project and with Furman University continues to hold the controlling interest. The Jamaican governmental bodies provided support through infrastructure, operating costs and financing for the trainees. The academic partners still provide guidance in crafting the curriculum and assuring quality standards are kept. Although in general the participants in this joint venture worked well together, some differences were noted, for example, some government departments were initially sceptical about the project because of bad experiences with similar ventures in the past. Additionally, there were conflicts between government departments as to who would assume control of the operation, and between the academic institutions as to the nature of the curriculum and accorded status of the teaching institution. Conflicts of interest between the objectives of quasi-public 'not for profit' organisations and privately funded profit-motivated firms also had to be overcome.

Once the project was approved, however, the government championed the effort through the Minister of Trade, Industry and Communications, Phillip Paulwell, who gave it his personal endorsement and attention. Further differences arose however, about plans for expansion of CIT, with Indusa and the university partners, concerned that the quality of tuition might be compromised, being more cautious and the government seeking to establish the scheme on a more island-wide basis, reflecting their desire to expand IT employment, not just in programming, but also in telemarketing and call centres, in an effort to diversify away from a dependency on a vulnerable tourism industry.

Despite these tensions, however, the collaboration has endured. Interviewees attributed this to the commitment shown by the partners, both the government's high level of involvement in sponsoring and funding the project, and Indusa's followthrough in hiring the trained programmers even if "their utilization factor for external revenue was $50 \%$ or below". Other contributing factors were the presence of senior representatives of the partnership on the managing board of the CIT and the chairmanship of that board by the government training agency HEART. One aspect that seemed to help was a common vision shared by the public and private partners that this project gave "the opportunity for an industry to develop to help [the Jamaican] economy", a view embraced by a government pursuing the path towards diversification of the economy by "get[ting] our brighter Jamaicans to upscale into programming". The need to involve local Jamaicans in the process of training and in improving their skills base through local projects was also mentioned among issues to be addressed in moving forward:

"And it's imperative that their government bring in incubator programmes where the Jamaicans and companies like Indusa Global are afforded some set-aside work, making sure that the industry can build a reputation and a core competence over time."(Carroll Rushing, Chairman, Indusa Global) 
Indusa's overseas clients include Computer Sciences Corporation, Applianceware, and the Ritz Carlton (INDUSA 2002) and it has initiated 'partnering' schemes with at least two of its customers, who have pledged to help sell the 'nearshore' option. The company also has contracts with Caribbean and Jamaican ventures, including Jamaican government agencies, demonstrating the level of trust that has been achieved in that arrangement. An Indusa Director described their strategy toward acquiring customers:

"Unless you have a substantial marketing capability, I think the idea will not take off. Also in the initial years, I think, you may or may not be able to retain all your clients. So you need to continually find a large basket of customers, ... finding different type of, or a wide variety of customers not just a particular type of customer"

Indusa's executive also complained about the "No problem, Mon" image of the Caribbean islands that made it difficult to convince potential clients to risk doing business there. Initially, as a means of overcoming this obstacle, the company presented an American appearance to its customers:

"Initially, when we started Indusa, selling the Jamaican programmers was not going to work. One of the things we did was to bring in our management from the key larger US companies. ...So some of the folks that we brought into Jamaica, from the US made a huge difference in our credibility factor."

In some instances, this "foreign" image still remains although many of Indusa's employees are local Jamaicans. As one local client put it:

"Well, the people that interfaced with me, I believe, are not Jamaican, so...I would refer to the company as in fact a foreign-based company. In terms of local talent, the talent out of CIT, they are not matured enough yet. They can be used as a team, but certainly they could not lead a team of this nature."

At the time of the study, numbers of staff had risen from an initial 15 to close to 100 , 83 of whom were CIT graduates. Indian workers comprised approximately $10 \%$ of Indusa's total workforce then, and were primarily employed in senior positions. Estimated revenues for 2002 were forecast at US\$ 3 million.

\section{Discussion}

The size of the IT sector in the Caribbean is difficult to ascertain, however one report estimates that it generates more than $\$ 200$ million for the region, employing some 5,000 people of which $36 \%$ are located in Jamaica and $41 \%$ in Barbados. Of these, $10 \%$ work directly with software development (Global Information Network 1999). For comparison, the overall population of Barbados is estimated at 277,264 and of Jamaica at 2,695,867 (CIA World FactBook 2003).

The Caribbean has a varied history, having been settled by the British, French, Spanish and Dutch at various points of their history (Williams 1970). As a result, most of the islands tend to retain much of their colonial history depending on where the settlers originated. In the former British colonies, for example, English is the official language spoken and educational and political systems tend to follow closely British standards as they existed in the mid $20^{\text {th }}$ century, when these islands first gained political autonomy. 
The cultural influences originate from the variety of people that have populated these countries and therefore comprise a mixture of African, Indian, European and some indigenous roots. Hence, the reggae music industry, which is indigenous to Jamaica and calypso, which started in Trinidad have their roots in African rhythms while the carnival tradition practiced in most islands is influenced by European and African cultural traditions (Horowitz 1971). The islands first became prized possessions of the respective European occupiers in the $17^{\text {th }}, 18^{\text {th }}$ and $19^{\text {th }}$ centuries due to the prosperity of the locally grown tobacco and sugar crops. With the demise of both of these industries, tourism has risen to prominence as a major foreign exchange earner for these islands.

Given this background information, it is clear that the availability of trained IT resources and supporting industries in these islands is fairly limited. Thus one can argue like Krishna et al. (2000), that Porter's "Diamond" may not be applicable in this context. Similarly, one can also argue, contrary to Krishna et al.'s (2000) case for India's competitive advantage, that the islands lack that cultural and historical heritage that might be expected to lead to success in software development. Both of the case study companies, moreover, are quite small (about 100 employees each, at the time of the study), and thus not internationally significant, when compared with multinational competitors. The degree of their impact on the local economies, nevertheless, may be substantial.

An analysis of the strategies used by these two companies to overcome the islands' apparent intrinsic deficiencies, may therefore provide insights as to what approaches may succeed in such non-traditional contexts. The analysis looks broadly at their strengths and weaknesses in six areas, viz. staffing, financing, clientele, marketing government support and integration into the local environment.

\subsection{Staffing}

Although PRT's stated objective was to train local staff, in practice most were eventually recruited from abroad. While this addressed the resource and skill deficiencies that might have otherwise halted the company's quick progress, it appears to have been short-lived. When staff attrition reached high levels in 1999, there was no opportunity to address this by resorting to local resources.

Indusa Global, on the other hand, adopted a more gradualist strategy of bringing in some expatriate Indians, training the locals and then building the company. In about five years, Indusa has only grown to about 100 persons and continues a steady, albeit slow, growth. Most of those employees are local Jamaicans. Although this approach may eventually be more sustainable, it does require a significant initial investment in training those human resources, a big risk if it proves unworkable.

\subsection{Financing}

PRT was financed initially through private capital and investments from prospective clients. After the IPO in 1997, its sources expanded to include funds from general 
investors, but its responsibilities toward its shareholders also became of paramount importance. The pressure on the company to post profits and its apparent failure to maintain its sales stream have been noted as contributors to its financial problems (Hopkins, 1999). The company's initial sources of capital, however, may have aided its quick growth, since essentially PRTB provided dedicated programming expertise to its client shareholders, a situation that may have been sustainable if the volume of incoming work had been consistent.

Indusa was mainly financed through private capital, while the CIT was funded partly by the government of Jamaica and its representatives and partly by Indusa. Using this approach, Indusa was able to involve the government from the beginning with its plans and to secure with them a working partnership in establishing the CIT. The government's financial stake in the operation increases the commitment it has to making the entire operation viable. The disadvantage of this relationship clearly lies in maintaining this partnership and balancing the objectives of the participants.

\subsection{Clientele}

PRT focused on US Fortune 1000 companies. This appears at first sight to have been a wise tactic, given that such companies tend to have large IT budgets and that having blue-chip customers would also enhance the company's prospects for further investment. It seemed, however, in the long run to have set up a dependence on these external clients to keep the company viable. The loss of a revenue stream from any of these clients would therefore have been significant. This dependence may have led to their eventual problems, since failure to attract new clients was cited as a possible reason for their financial difficulties.

Unlike PRTB, Indusa's special relationship with the Jamaican government allowed it to target local and Caribbean customers as well as external US clients. This strategy allowed Indusa some degree of independence from the variations in the US demand for software services as well as a way of developing local expertise and possible niche market areas, strategies promoted in the literature (Heeks 1999; Schware 1992). Naturally such small economies as Jamaica cannot totally escape some dominance from the larger US market, given its proximity and its reputation as one the largest global software markets, hence at some level dependence on the US market for the bulk of its operation would still exist for Indusa.

\subsection{Marketing}

PRTB was seen to have failed to differentiate itself sufficiently from other more wellknown alternatives to nearshore software outsourcing, like India, relying instead on patterns of offshore outsourcing that had worked for the parent company such as "body-shopping". In retrospect, it seemed that nearshore might have required a different more focused marketing emphasis, such as that proposed by its practitioners. Nevertheless, in attempting to sell a new concept, reliance on more familiar modes of operation may have assisted the company at its inception. 
In response to this challenge, Indusa initially concentrated on its image and recruited senior staff from reputed American companies, and its programming staff from India. Other strategies pursued by Indusa were to develop a large and varied customer base in various industries and to initiate partnering schemes with customers, who would commit to actively helping to sell the nearshore concept to external clients. The initial recruitment tactic and the customer strategies could be seen as a means to increase credibility and spread risk, which appeared, at least in the short term, to provide enough work to sustain the enterprise. Selling nearshore, however, still remains a risky affair, as it is seen to be a new, untested concept (Abbott and Jones 2003).

\subsection{Government Support}

Government support in the case of PRTB seems to have been fairly passive. Besides affording logistics support, the government appeared not to play a proactive role in PRTB's establishment. Instead, it seemed that PRTB was expected to build infrastructure, attract clients and provide employment. Although this approach enabled PRTB to make progress unimpeded by government bureaucracy, the expectations raised at their initial arrival on the island were hardly met. Providing viable investment opportunities for software exporting companies such as PRTB is thought to be an important government strategy (Kim et al. 1989), however, further roles may need to be identified to make those investments last in such small economies.

With Indusa, it appears that the Jamaican government actively courted the owners to invest in Jamaica, and eventually gave full political and some economic support for the project. Thus, as Heeks and Nicholson (2002) and Lipsey (1997) have recommended, the government's proactive role and continued involvement, through CIT, seemed to have contributed to Indusa's initial success as an offshore software outsourcing entity. Although the school was initially built to train Indusa's employees, its existence could continue to provide resources for attracting other investors. The degree of closeness of that interaction and the degree of commitment, however, may have to be negotiated in order to maximise mutual benefits reflecting the different parties' distinct priorities. Finding a balance between these may be critical to long-term success (Abernethy and Reichgelt 2001).

\subsection{Integration into Local Environment}

PRT, through its expatriate recruitment strategy and dependence on external clientele does not seem to have been particularly integrated into the local environment. Besides the salaries earned by the local Barbadians working there and the profits gained by those involved in providing ancillary services, not much would have been generated for the local economy. This type of activity is referred to as creating "export enclaves" where the local environment does not benefit much from the activities of software exporting companies (Heeks 1999). This external focus was not stated as part of their original objectives for the enterprise, but seemed to have evolved as a means of survival. For example, the company needed to support its 
growing expansion and thus could not solely rely on resources within Barbados to do so.

Indusa appears to have both an external focus and an internal presence through its strategies of having an incubation and image-building period and then involving government and educational institutions, tying its success to their active involvement in that collaboration. Indusa's capacity for employing CIT graduates, unfortunately, depends on the state of its major market, the US. The CIT operates, however, more and more as a Jamaican entity and can thus continue to provide a means by which the local population can obtain marketable skills, and the ability to generate income independent of Indusa. Providing the skills for building Jamaica's local IT capability is therefore an intangible asset that the Indusa scheme offers, and which according to the literature can help the country promote its software export strategy (Schware 1992; Heeks 1999). Nonetheless despite its attempts at local assimilation, Indusa was still viewed locally as a foreign entity and its Jamaican programmers as not having that much credibility.

\subsection{Assessing the Outsourcers' Strategies}

Most of the frameworks reviewed mention human resources as an important aspect of the process of developing a viable software export industry (Heeks and Nicholson 2002; Krishna et al. 2000; Porter 1990), although in the cases assessed by these frameworks, lack of sufficient trained resources was not raised as an issue. In the case of the Caribbean islands, it was a major issue to be overcome, which led to the approaches used. The same sort of deficiency can probably be expected of any other small developing region attempting to use software export to their economic advantage. Of the two strategies, the one that seems to have some sustainable potential is the Indusa approach of training the local population. Those frameworks that promote developing a homegrown software business also stress the need for developing indigenous talent, thus suggesting that the Indusa approach may have support within the literature.

Financing is mentioned in the frameworks in connection with government policies such as allowing tax breaks and lifting import restrictions so as to ensure that software exporters can be profitable (Heeks and Nicholson 2002; Kim et al. 1989). In both the cases reviewed, government's policies were in line with these suggested positions. Both companies were, however, foreign to the islands and thus secured their financing externally. Obtaining foreign equity in such a manner was seen as part of India's externally focused "export-oriented" development strategy (Schware 1992). Of the two cases, it appeared that the less externally focused strategy, the Indusa approach, which collaborated with local financiers, had the potential staying power.

Building close client relationships that foster trust and international linkages was seen in at least one framework to be an efficient aspect of a software-export strategy (Heeks and Nicholson 2002). Both PRTB and Indusa had such linkages and close client relationships, however, it appeared that the degree of dependency was less in the latter case, thus allowing them perhaps more independence and leverage. Such 
strategies might be especially beneficial for smaller countries that, in general, do not already possess strong trade or communication links with more industrialised nations.

With regard to marketing, promoting specific areas of expertise or "niches" is mentioned in some of the literature as a viable export strategy especially for newcomers to the industry or, perhaps as in this case, smaller countries with less resources and smaller economies (Heeks and Nicholson 2002; Heeks 1999; Correa 1996). Interviews with the nearshore outsourcers revealed that this was a desired, if not sometimes applied strategy.

Practically all of the frameworks mentioned to some degree government's role in supporting software export especially in small developing countries. Perhaps the most comprehensive of these is (Heeks and Nicholson 2002) where governments are expected to take active control of the direction of the software export industry in the developing country. In the cases reviewed, it was seen that the greater commitment on the part of government was realised with their active involvement, financially and politically in the establishment of the Indusa/CIT enterprise. Their support and ongoing involvement would be secured due to their stake in the success of failure of the project.

Although not mentioned specifically in any of the frameworks, the outsourcing company's level of integration within the society appears also to have some influence on the sustainability of the project and is evident as an underlying aspect of the previously discussed approaches. It appears that the more integrated with the local milieu is the scheme adopted by the outsourcer, the more is its potential for succeeding. Perhaps the framework that most closely approaches this idea is the software development system diamond (Krishna et al. 2000) where cultural aspects affecting the success of software exporting are highlighted and it is argued that traits indigenous to the country had more effect on its success as a software exporter than economic aspects such as Porter's determinants. Likewise, the "soft" aspects of Indusa's approach and PRTB's original ideas of helping the community to develop its own IT capability seemed to be productive and sustainable ideas, which perhaps are useful within communities such as this which more often lack other substantial resources to help achieve sustainability. These ideas perhaps adhere more closely to notions developed in other areas of IS research concerned with cultural adaptation of IT in developing countries (Walsham 2001; Westrup et al. 2000). These authors emphasise adaptation and compromise on the parts of both those bringing the foreign technology into the country and those expecting to benefit from it. Assimilating into the local context and demonstrating long term commitment on the part of the foreign entity and appropriating and adapting the technology on the part of the local community are the types of approaches promoted.

\section{Conclusion}

The findings discussed above may therefore have implications for the implementation of strategies for software export in developing countries, especially where significant factors considered as precursors to success are absent. This suggests that pre-existing frameworks may need to be tailored for such contexts in order to make them viable. 
The results presented here, however, are preliminary and subject to limitations in the scope of the study. Their generalisability is therefore constrained. Nearshore software outsourcing ventures in the Caribbean, for example, appear to be somewhat based on opportunistic initiatives instigated by external entities rather than a concerted strategy by private or public sector, hence, studying these enterprises is limited to the small samples that are available. The companies researched were also attempting to sell a new concept in an untested environment, the so-called 'nearshore software outsourcing' option, (Abbott and Jones 2003) which may account for the strategies that were adopted. In the absence of the existence of a larger sample these companies, it is difficult to draw conclusions as to common patterns of success among them and the possible reasons. Also other factors, intrinsic to the islands themselves, (small size, dependence on a specific industry) may have led to the choice of certain strategies and their eventual outcome. There may still be significance, however, in the fact that both cases exhibited consistent themes.

It has been noted that, due to an increasingly networked economy, brought on by the spread of ICTs and the forces of globalisation small states may suffer marginalisation (Castells 1996). By becoming part of a globalised software industry, these states may stand a chance of being included in international trading links. Similarly, places not usually associated with IT work may become important bases for software production, given the continuing growing demand for software and the skill shortages worldwide. In this paper, the proximity of these particular places was seen as a strategic benefit. In the future, other non-traditional areas may be chosen on the basis of other considerations such as political stability or security assurances. Hence, a better understanding of viable approaches to be used in such contexts would be very useful to both governments and investors alike. Not only would these results be applicable to such small island developing states, as have been discussed here, but perhaps also to underdeveloped areas of both developed or developing countries such as non-urban centres or depressed economic regions. Similar strategies for development through software production could be seen to be pertinent.

Further research on software-exporting strategies in such non-traditional contexts is clearly necessary in order to determine if the sorts of preliminary observations given in the paper can affect approaches to this industry. In the Caribbean context, longitudinal case studies of software exporters can be carried out, that can look at trends over time, with respect to changes in government policy and company strategies and their effects, the development and progress of the relationship between government and these companies and the level of impact of the industry on the economy and society in order to develop a better picture of approaches that work. Such studies would either reveal inconsistencies in, or provide support for, the current observations. In other non-traditional contexts, a similar approach can be taken. Comparisons of the trends observed over time to policies and strategies in place in existing software-exporting countries could also be undertaken to ascertain what, if any, modification to current suggested frameworks, is advisable. Research of this type is also applicable, in a more general way, to studies on the effects of global initiatives applied to local contexts. 


\section{References}

Abbott, P., and Jones, M. "The Importance of Being Nearest: Nearshore software outsourcing and globalisation discourse," in Global and Organizational Discourse about Information Technology, E.H. Wynn, E.A. Whitley, M.D. Myers, and J.I. DeGross (eds.), Kluwer Academic Publishers, Boston, MA, 2003, pp. 395-397.

Abernethy, K., and Reichgelt, H. "A Case Study on Establishing Linkages Between Universities, Private Sector Companies and Governmental Organizations" Proceedings 2001 Conference on Emerging Issues in Business and Technology, College of Business and Technology, Western Illinois University, Macomb, Illinois, 2001.

Balasubramanyam, V. N., and Balasubramanyam, A. "International Trade in Services: The Case of India's Computer Software," The World Economy (20:6), September 1997, pp. 829-843.

Carmel, E. Global Software Teams: Collaborating Across Borders and Time Zones, Prentice Hall, Upper Saddle River, NJ, 1999, pp. 3-21.

Carmel, E., and Agarwal, R. "Tactical Approaches for Alleviating Distance in Global Software Development," IEEE Software (18:2), March/April 2001, pp. 22-29.

Castells, M. The Rise of the Network Society, Oxford University Press, Oxford, 1996, pp. 66-148.

CIA World FactBook CIA - The World Fact Book 2003 - Jamaica, CIA World FactBook website section, accessed 23 December 2003. http://www.cia.gov/cia/publications/factbook/print/jm.html

CIA World Fact Book CIA - The World Fact Book 2003 -- Barbados, CIA World FactBook website section, accessed 23 December 2003. http://www.cia.gov/cia/publications/factbook/print/bb.html

Correa, C.M. "Strategies for Software Exports from Developing Countries," World Development, (24:1) January 1996, pp. 171-182.

Global Information Network "UK: Technology Jamaica - Software Industry Poised for Take-off," Global Information Network, IPS News Feed, 23 February 1999.

Heeks, R. India's Software Industry: State Policy, Liberalisation and Industrial Development, Sage Publications Inc., New Delhi, 1996.

Heeks, R.B. "Software Strategies in Developing Countries" Communications of the ACM (42:6), June 1999, pp. 15-20.

Heeks, R., and Nicholson, B. "Software Export Success Factors and Strategies in Developing and Transitional Economies" Proceedings IFIP Working Group 9.4 Conference, IIMB Bangalore, India, 29-31 May 2002, pp. 311-331. 
Herbsleb, J.D., and Moitra, D. "Global Software Development," IEEE Software (18:2), Mar/Apr 2001, pp. 16-20.

Hopkins M. S. "The Antihero's Guide to the New Economy," Inc. (20:1), January 1998, pp. 36-45.

Hopkins M. S. "Paradise Lost,” Inc. (21:16), November 1999, pp. 66-74.

Horowitz, M.M. Peoples and cultures of the Caribbean; an anthropological reader, Natural History Press, Garden City, NY, 1971.

INDUSA IndusaLLC Press Release - SkyBusiness, September-October 2002, Indusa Global website section, accessed 26 October 2002. http://www.indusallc.com/html/mediacoverage_SkyNew.html

Kim, C., Westin, S., and Nikhilesh, D. "Globalization of the Software Industry: Trends and Strategies," Information \& Management (17:4), 1989, pp. 197-206.

King, J. "Sun and Pay Lure Coders to Barbados Outsourcer," Computerworld (33:11), 15 March 1999, p. 24.

Krishna, S., Ojha, A. K., and Barrett M. "Competitive Advantage in the Software Industry: An Analysis of the Indian Experience" in Information Technology in Context, C. Avgerou and G. Walsham (eds.), Ashgate, Aldershot, 2000, pp. 182-197.

Lacity, M.C., and Willcocks, L.P. Global Information Technology Outsourcing, John Wiley \& Sons, Ltd., Chichester, 2001, pp. 26-28.

Lapper, R., and Tricks, H. "Inside Track: Nearshore contracts flow Mexico's way," Financial Times, 17 May 1999, p. 16.

Lipsey, R.G. "Globalization and National Government Policies: An Economist's View" in Governments, Globalization, and International Business, J.H. Dunning (ed.), Oxford University Press, Oxford, 1997, pp. 73-113.

NASSCOM IT software and services market, Nasscom website section, accessed 31 October 2003. http://www.nasscom.org/artdisplay.asp?Art_id=1636

Porter, M. "The Competitive Advantage of Nations" Harvard Business Review (68:2), Mar/April 1990, pp. 73-93.

PRT Annual Report of PRT Group Inc., Securities and Exchange Commission, Washington DC, 31 December 1997.

PRT Annual Report of PRT Group Inc., Securities and Exchange Commission, Washington DC, 31 December 1999. 
Reich, R.B. The Work of Nations, Simon \& Schuster, London, 1991, pp. 208-224.

Schware, R. "Software Industry Entry Strategies for Developing Countries: A 'Walking on Two Legs' Proposition," World Development (20:2), February 1992, pp. 143-164.

Tessler, S. and Barr, A. "Software R\&D Strategies of Developing Countries," Graduate School of Business, Stanford University, Stanford Computer Industry Project (SCIP) Position Paper, CFR197, 9 January 1997.

Walsham, G. Making a World of Difference: IT in a Global Context, Wiley \& Sons, Chichester, 2001, pp. 207-233.

Westrup, C., Jaghoub, S.A., Sayed, H.E. and Liu, W. "Taking Culture Seriously: ICTs, Cultures and Development" Proceedings of IFIP WG9.4 Working Conference on ICTs and Development: New Opportunities, Perspectives and Challenges, Bangalore, India, 24-26 May 2000.

Williams, E. From Columbus to Castro, The History of the Caribbean 1492-1969, Vintage, London, 1970. 